\title{
The Use of System Codes in Scaling Studies: Relevant Techniques for Qualifying NPP Nodalizations for Particular Scenarios
}

\author{
V. Martinez-Quiroga and F. Reventos \\ Institute of Energy Technologies, Technical University of Catalonia, Av. Diagonal 647, 08028 Barcelona, Spain \\ Correspondence should be addressed to V. Martinez-Quiroga; victor.martinez@nortuen.com
}

Received 2 September 2013; Accepted 12 December 2013; Published 10 February 2014

Academic Editor: Eugenijus Ušpuras

Copyright (c) 2014 V. Martinez-Quiroga and F. Reventos. This is an open access article distributed under the Creative Commons Attribution License, which permits unrestricted use, distribution, and reproduction in any medium, provided the original work is properly cited.

\begin{abstract}
System codes along with necessary nodalizations are valuable tools for thermal hydraulic safety analysis. Qualifying both codes and nodalizations is an essential step prior to their use in any significant study involving code calculations. Since most existing experimental data come from tests performed on the small scale, any qualification process must therefore address scale considerations. This paper describes the methodology developed at the Technical University of Catalonia in order to contribute to the qualification of Nuclear Power Plant nodalizations by means of scale disquisitions. The techniques that are presented include the so-called $K_{v}$-scaled calculation approach as well as the use of "hybrid nodalizations" and "scaled-up nodalizations." These methods have revealed themselves to be very helpful in producing the required qualification and in promoting further improvements in nodalization. The paper explains both the concepts and the general guidelines of the method, while an accompanying paper will complete the presentation of the methodology as well as showing the results of the analysis of scaling discrepancies that appeared during the posttest simulations of PKL-LSTF counterpart tests performed on the PKL-III and ROSA-2 OECD/NEA Projects. Both articles together produce the complete description of the methodology that has been developed in the framework of the use of NPP nodalizations in the support to plant operation and control.
\end{abstract}

\section{Introduction}

In September 1988 the USNRC approved a revision of the ECCS rule (10 CFR part 50) by which BEPU calculations could be used for licensing. Likewise, CSAU methodology (Figure 1) was presented by NRC [1] in order to establish the requirements for quantifying code uncertainties in specific scenarios and NPPs. The CSAU guidelines provided a very valuable roadmap for developing specific uncertainty methodologies [2-4] and it showed the relevance of scaling issues when using system codes for ECCS licensing.

One of the CSAU methodology requirements (see step 9 in Figure 1) was to determine code accuracy. If the scenario involves ECCS actuation it is unavoidable to design scaled down facilities for the validation of system codes. And it is just at this point where the so-called "scaling controversy" starts. Experience has shown that there is no consensus for matching code validation on the scale of test facilities with code validation for a specific commercial NPP and a specific scenario. Objections are mainly based on two features:

(a) the design of a test facility which "cannot completely satisfy all the scaling requirements. Thus scaling distortions are unavoidable (...)." [5],

(b) intrinsic limitations of thermalhydraulic codes, namely, the simulation of two-phase flow regime transitions and the impossibility of qualifying their closure equations under transient and nondeveloped flow conditions [6].

Along these lines, several scaling analysis philosophies have been developed (H2TS $[7,8])$ together with the Ishii three-level scaling approach [5]. Such developments have been applied in the design of new test facilities (APEX [9] and PUMA [5]) in order to identify and evaluate scaling distortion on experimental data. Furthermore, there is still 


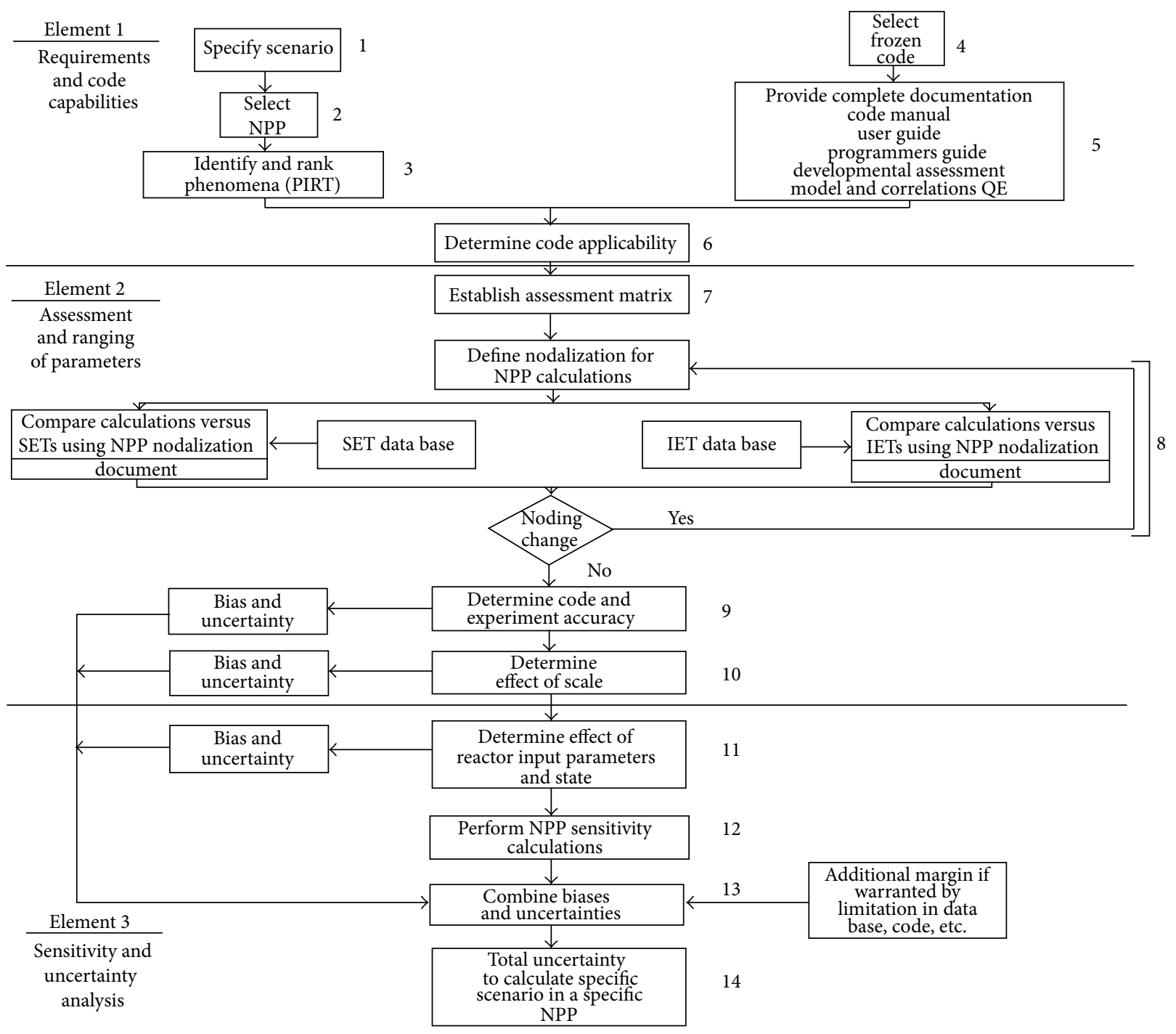

Figure 1: CSAU methodology.

a lack of a global response on the subject of scaling code capabilities to extend the experience acquired through experiments to the use of BEPU calculations for the licensing of NPPs. Part of the scientific community considers the use of system codes inappropriate and proposes quantitative methodologies for NPP design and safety analysis (FSA methodology, [10-12]). Alternatively, D'Auria and Galassi [6, 13] developed the UMAE methodology for determining the uncertainty and similarity associated with the simulation of the ITF experiments in different nodalizations and suggested a "roadmap to scaling" in order to follow up and progress on the guidelines that were set up in the CSAU methodology.

Even though the main code scaling techniques presented in this paper could be perfectly integrated within the "roadmap to scaling" concept presented in [6] and UMAE methodology presented in [13], it is not within the scope of the present methodology to further study the scaling of the capabilities of the system codes. Otherwise, Best Estimate Codes are widely applied within the nuclear industry for operational support and safety assessment. "UPC Scaling-up methodology," explained in Section 2, aims to be a guideline for validating and improving NPP nodalizations with the knowledge obtained from the modeling of ITF tests. The aim is to provide a tool for qualifying nodalizations.

This paper, along with that of [14], describes the methodology developed at Technical University of Catalonia in order to contribute to the qualification of Nuclear Power Plant nodalizations using scaled calculations. The paper explains the concepts and general guidelines of the method, while the other paper [14] provides more details on a specific application. Since it is focused on concepts and guidelines, only a few results are shown. In the second paper, the established procedure is applied to the scaling discrepancies that appear between the posttest simulations of PKL-LSTF 
Counterpart Tests performed on the PKL-III and ROSA-2 OECD/NEA Projects. Both papers together supply a complete description of the methodology that has been developed in the framework of the use of NPP nodalizations in the support to plant operation and control.

\section{NPP Nodalization Qualification and Quality Guarantee Procedures}

Computational analysis and NPP nodalizations are both a widely used and well-developed application in nuclear engineering not limited to licensing. Most of the tasks, related to the support to plant operation and control, are extensively discussed in two different IAEA safety reports $[15,16]$. Some of them can be summarized as in the detailed description of [17].

(a) TH analysis of PSA sequences, mainly those of Level 1.

(b) Analysis of actual transients.

(c) NPP start-up test analysis.

(d) EOP validation analysis.

(e) Transient analysis for training support.

(f) Design modifications.

(h) Improvement of plant availability.

Results presented by the UPC in [17-21] show the usage and effective application of NPP nodalizations in the support to plant operation and control. In that sense, the quality assurance procedures play a key role in the continuous improvement of an NPP nodalization. Examples of NPP nodalization qualification methods are as follows.

(a) UPC Advanced Qualification Process of ANAV NPP Models [20]. The UPC developed advanced qualification matrices that allow the robustness of nodalizations for different configurations and plant transients to be checked. These matrices relate several components of the plant to different real transients at different plant configurations.

(b) Giralda Methodology. Developed by Garcia-Delgado et al. [22] and recognized by the CSN, it is a quality guarantee methodology used for both core and fuel licensing and design. It has been used on Cofrentes NPP nodalizations based on CASME and SIMULATE codes.

(c) Bonuccelli Qualification Methodology. VVER-1000 nodalizations were developed and qualified [23] following the Bonuccelli guidelines [24] for validating nodalizations on steady-state and on-transient levels.

As regards scaling, plant-scaled calculations (called $K_{v^{-}}$ scaled analyses following [6]) are strongly involved in the qualification process of nodalizations. They consist of adjusting the transient conditions of an NPP nodalization to the test conditions of an ITF experiment. It allows the behavior of NPP and ITF nodalizations to be compared under the

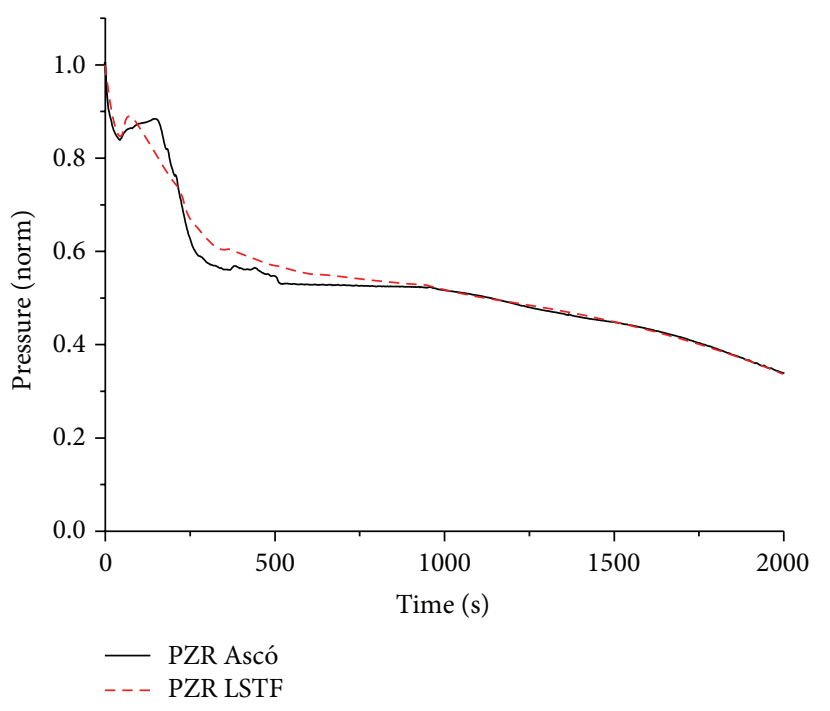

Figure 2: Primary pressure (picture from [23]).

same conditions in order to check the capabilities of an NPP nodalization and to improve it if required. Several plant-scaled calculations have been done during recent years [25-29]. Related to the results of [23], Figures 2 and 3 compare a PWR NPP nodalization with an LSTF posttest calculation in which CCFL and U-tube liquid accumulation took place. The nodalization of the U-tubes in the NPP nodalization was improved by following the conclusions of the LSTF posttest analysis. Results for the plant-scaled calculation showed that a similar system depressurization in both nodalizations (Figure 2) led to liquid accumulation taking place in a qualitatively similar way (Figure 3). This would be a clear example of how ITF modeling can improve NPP nodalizations. More detailed information about plantscaled calculations can be found in Section 3.3.

\section{UPC Scaling-Up Methodology}

UPC scaling-up methodology follows the general guideline given in [13]. An important development has been performed in order to identify and justify discrepancies that appear between counterpart simulations at different scales and designs. It is a systematic procedure for qualifying NPP nodalizations taking advantage of the experience acquired through the posttest analysis of ITF experiments. It is devoted to the modeling qualification, which implies that the methodology can only be applied to those phenomena that have been well reproduced in ITF posttest analyses, and that scaling analyses are only performed through code simulations (and do not involve experimental data).

There are two main factors that affect scaling up of ITF posttest simulations:

(a) the scaling-down criterion used for the design of the ITF, 


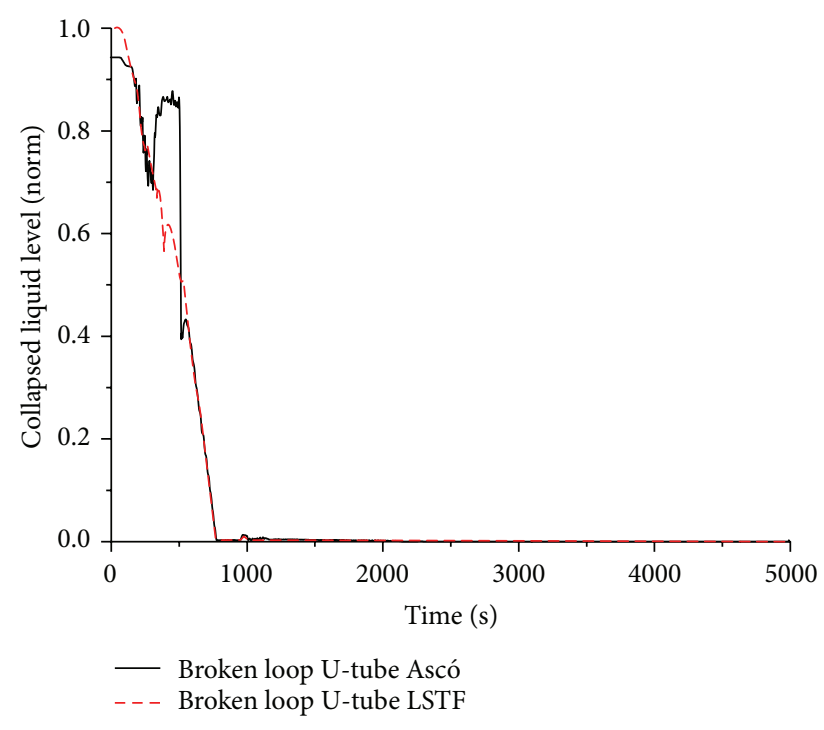

FIgURE 3: U-tube collapsed liquid level (picture from [23]).

(b) the differences of configuration between the ITF and the NPP.

In order to analyze both, the UPC scaling-up methodology uses two approaches, "scaled-up nodalizations" and "hybrid nodalizations." It is crucial that they are not confused with the approaches previously presented. Sections 3.4.2 and 3.5 provide some details on how each nodalization is prepared. The so-called "scaled-up nodalizations" analyze the effect of the ITF scaling criterion in a scaled-up calculation. On the other hand, the "hybrid nodalizations" are defined as modified scaled-up ITF nodalizations in which some components have been adjusted to resemble the configuration of the NPP components. The aim is to evaluate the influence of each feature of the configuration on the ITF simulation results irrespective of the scale.

The "UPC scaling-up methodology" is shown in Figure 4. The procedure is divided into several steps.

(a) To identify a specific scenario for qualifying NPP nodalizations with ITF tests that reproduces its related phenomena. A validation matrix must be defined in order to relate the ITF tests with the particular phenomena to be qualified in the selected scenario "NPP scenario validation matrix".

(b) To validate ITF nodalizations and ITF tests selected in the NPP validation matrix "ITF test \& models Validation".

(c) To perform a preliminary plant scaled calculation with the NPP nodalization "NPP scaled calculation".

(d) To analyze and establish the scaling and design effects in the simulation results by using generated scaled-up and hybrid nodalizations "scaling effect analysis and design effect analysis". In this step, it is essential to carry out the analyses in series and not in parallel in order to avoid compensating errors.

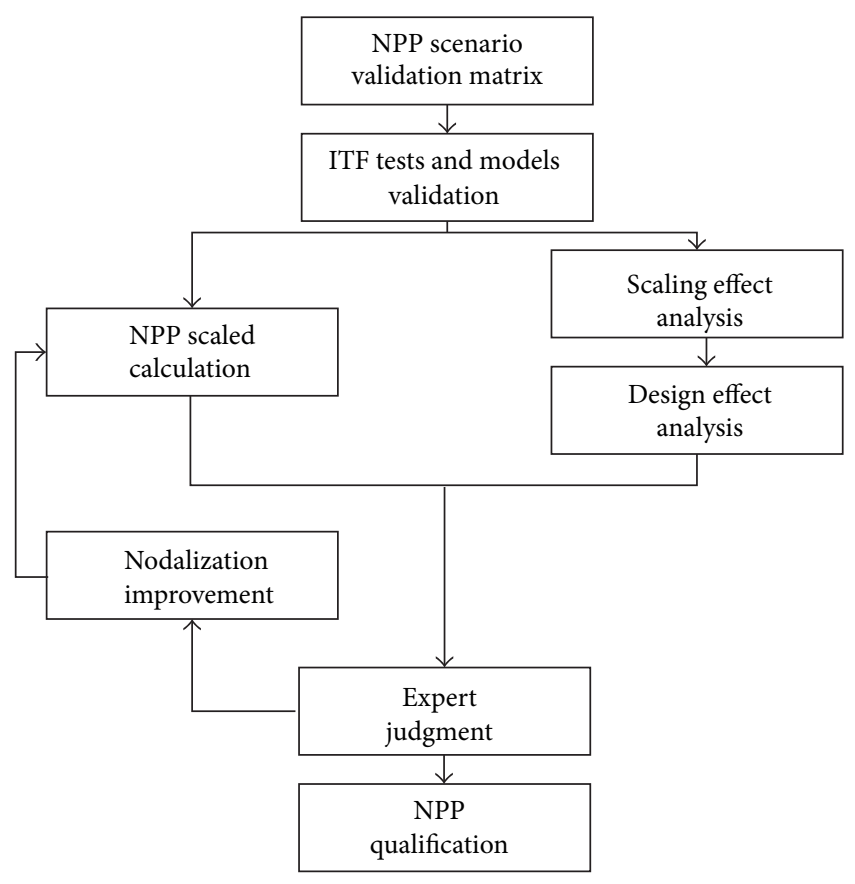

FIGURE 4: UPC scaling-up methodology.

(e) To perform an expert judgment by comparing the results of step (C) combined with conclusions of step (D) "expert judgment". If results are not consistent, the analyst should improve the NPP nodalization with those modeling remarks obtained from the ITF posttest analysis "nodalization improvement". In the case that the NPP nodalization and the plant scaled calculation results are consistent with the posttest calculation and with the scaling and design effect analysis, the NPP nodalization can then be considered to be qualified "NPP qualification".

Each of the steps of the "UPC scaling-up methodology" is explained in more detail in the following subsections. The results that are shown are from [14], in which the procedure is applied to analyze the scaling discrepancies that appeared between the posttest simulations of PKLLSTF counterpart tests performed within the PKL-2 and the ROSA-2 OECD/NEA projects. The discrepancies found are due to differences between the CET and the PCT.

3.1. NPP Scenario Validation Matrix. The initial step of the UPC scaling-up methodology requires the analyst to decide the type of scenario for which he wants to validate the NPP nodalization. Once the scenario has been selected, three main features have to be analyzed:

(a) the relevant thermal-hydraulic phenomena occurring in the selected scenario,

(b) the design of the ITFs employed in the analysis,

(c) the choice of ITF experiments.

The aim is that the analyst finds ITFs with similar design to his NPP nodalization in which selected tests include the 
TH phenomena related to the specific scenario. In that sense, the ITF system description reports, ITF test reports, and, most of all, CSNI code validation matrices [30] are therefore of exceptional value.

Once the TH phenomena have been decided upon and the most convenient ITFs have been chosen, an "NPP scenario validation matrix" must be defined in order to ensure which phenomena can be tested by system codes. In Table 1 there is an example of a validation matrix for the PWR SBLOCAs and IBLOCAs. In this matrix, the phenomena suggested by the CSNI matrices [30], the LSTFPKL counterpart test reports, and LSTF Test 2 report are related to 5 tests performed in 3 different ITFs (LOBI, LSTF, and PKL).

When ITF tests are chosen, it is important to pay attention to counterpart tests (tests with identical boundary conditions performed at facilities at different scales) because they allow to check, for different scales and designs, if the codes and the ITFs nodalizations can reproduce the same phenomena. This will not ensure that these phenomena can be extrapolated to the NPP scale (as already mentioned, this point is not within the scope of this methodology), but it will be very effective for translating ITF modeling experience to NPP nodalization qualification because the analyst can evaluate whether the same modeling criteria have been used for different scales and designs. In the example of Table 1 , four of the ITF tests are counterpart experiments and establish a link both between PWR Siemens/KWU (LOBI, PKL) and Westinghouse (LSTF) designs, together with three different scales (1:48 for LSTF, $1: 145$ : for PKL, and 1:700 for LOBI).

3.2. Validation of ITF Tests and Nodalizations. In the second step, the analyst should perform posttest analyses of the ITF experiments chosen in the "NPP scenario validation matrix." The aim of this step is to ensure the quality of the results and to draw conclusions on code modeling. The work of the analyst should therefore be focused on two features:

(1) qualifying the ITF nodalizations for several tests beyond those selected in the validation matrix,

(2) assuring the robustness of the nodalization to minimize user effect and compensating errors.

About these points, some papers have been presented during the last few years [31,32] in order to ensure the quality of modeling through posttest analyses. Both are based on two main ideas: the improvement of ITF nodalizations with the continuous simulation of posttests and regular checking of nodalization changes by reexecuting all the previous tests with the latest version of the ITF nodalization. The idea is to ensure that both a unique and sufficiently detailed nodalization can reproduce the whole posttest library while keeping (or improving) the degree of agreement with experimental results.

Once the ITF nodalization has been qualified and the required tests of the validation matrix have been simulated, phenomena that have been validated for at least two facilities at different scales and designs can be used for qualifying NPP nodalizations. The modeling guidelines derived in both cases
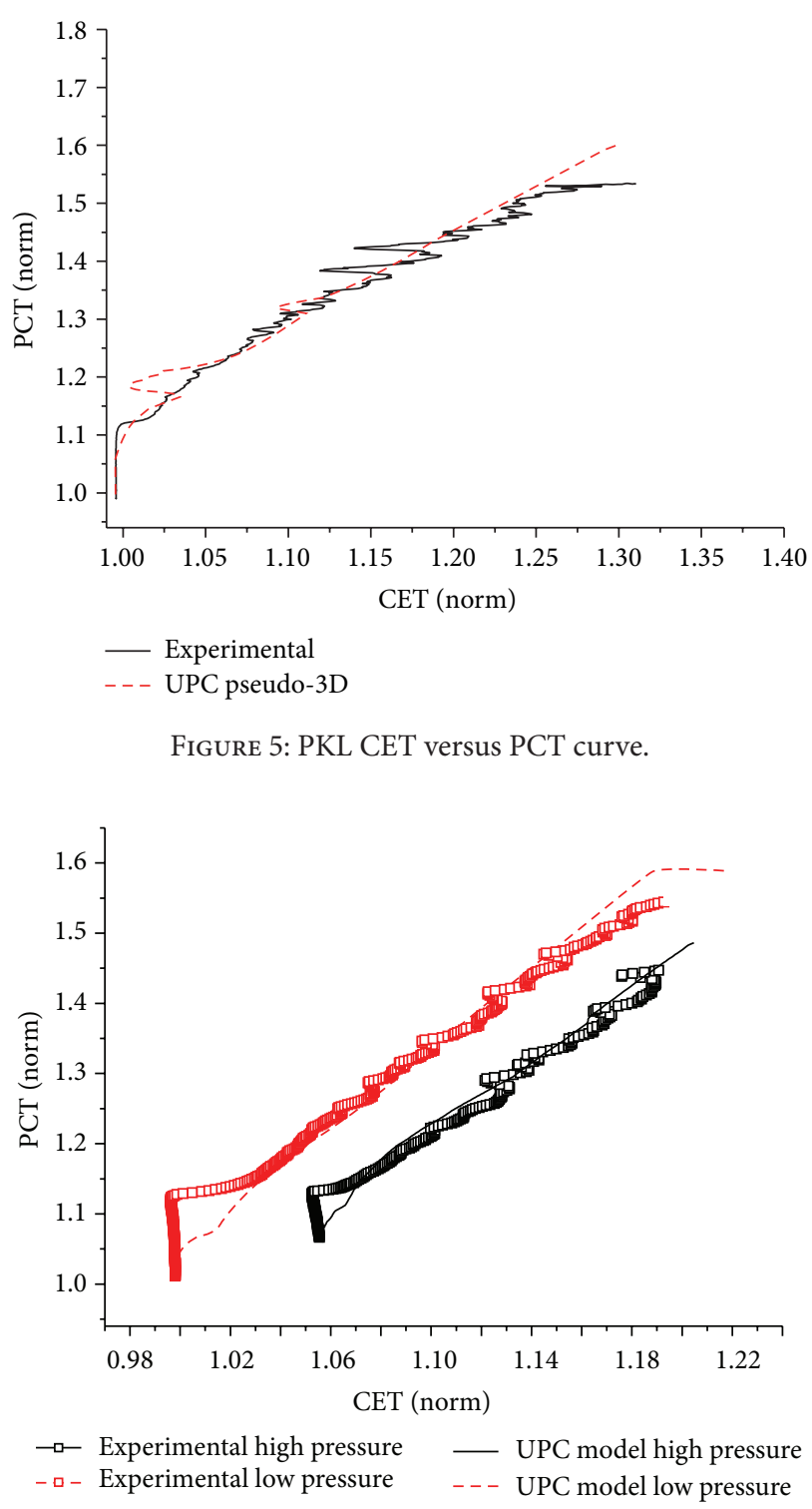

Figure 6: LSTF CET versus PCT curves.

need to be consistent. To achieve this, expert judgment will be essential. If counterpart tests have been validated for the same phenomena with the same modeling conclusions, a plantscaled calculation and scaling and design effect analyses will be performed for the counterpart test in which the design of the ITF is closest to the NPP nodalization.

In [14] both LSTF and PKL counterpart tests were validated for phenomena related to the correlation between CET and PCT. Better agreement was achieved by improving the core nodalization using a pseudo-3D modeling. The results showed a closer agreement in both cases (Figures 5 and 6).

Both nodalizations were previously qualified with the ROSA posttest 3-1 ([33]) and posttest 3-2 ([34]) for LSTF and PKL III Test E1.1, E2.2 ([28]) and others ([35, 36]) for PKL.

3.3. NPP Scaled Calculation. A plant-scaled calculation is a system code simulation in which defined ITF test conditions 
TABLE 1: NPP SBLOCA/IBLOCA validation matrix.

\begin{tabular}{|c|c|c|c|c|c|}
\hline \multirow{2}{*}{ Test phenomena } & \multicolumn{2}{|c|}{ Counterpart tests } & \multicolumn{2}{|c|}{ Counterpart tests } & \multirow{2}{*}{ ROSA 2 test 1} \\
\hline & PKL III G7.1 & ROSA 2 Test 3 & BL-34 (LOBI) & SB-CL-21 (LSTF) & \\
\hline 1-phase natural circulation & & & $\mathrm{X}$ & $\mathrm{O}$ & \\
\hline 2-phase natural circulation & $\mathrm{X}$ & $\mathrm{X}$ & $\mathrm{X}$ & $\mathrm{O}$ & \\
\hline Reflux and condensation & $\mathrm{X}$ & $\mathrm{X}$ & $\mathrm{X}$ & $\mathrm{O}$ & \\
\hline Asymmetric loop behavior & $\mathrm{X}$ & & & $\mathrm{O}$ & \\
\hline Break flow & $\mathrm{X}$ & $\mathrm{X}$ & $\mathrm{X}$ & $\mathrm{O}$ & $\mathrm{X}$ \\
\hline Phase separation without mixture level formation & $\mathrm{X}$ & $\mathrm{X}$ & $\mathrm{O}$ & $\mathrm{O}$ & $\mathrm{X}$ \\
\hline Mixture level and entrainment on SG secondary side & $\mathrm{X}$ & $\mathrm{X}$ & $\mathrm{X}$ & $\mathrm{O}$ & \\
\hline Core mixture level & $\mathrm{X}$ & $\mathrm{X}$ & $\mathrm{X}$ & $\mathrm{O}$ & $\mathrm{X}$ \\
\hline Stratification in horizontal pipes & $\mathrm{X}$ & $\mathrm{X}$ & $\mathrm{X}$ & $\mathrm{O}$ & $\mathrm{X}$ \\
\hline Phase separation T-junction and effect on break flow & $\mathrm{X}$ & $\mathrm{X}$ & & $\mathrm{O}$ & $\mathrm{X}$ \\
\hline ECC-mixing and condensation & $\mathrm{X}$ & $\mathrm{X}$ & $\mathrm{X}$ & $\mathrm{O}$ & $\mathrm{X}$ \\
\hline Loop seal clearing & & & $\mathrm{X}$ & $\mathrm{X}$ & $\mathrm{X}$ \\
\hline Pool formation in UP/CCFL & & & & $\mathrm{O}$ & $\mathrm{X}$ \\
\hline Core-wide void and flow distribution & $\mathrm{X}$ & $\mathrm{X}$ & & $\mathrm{O}$ & $\mathrm{X}$ \\
\hline Heat transfer in covered core & $\mathrm{X}$ & $\mathrm{X}$ & $\mathrm{X}$ & $\mathrm{O}$ & $\mathrm{X}$ \\
\hline Heat transfer in preuncovered core & $\mathrm{X}$ & $\mathrm{X}$ & $\mathrm{X}$ & $\mathrm{O}$ & $\mathrm{X}$ \\
\hline Heat transfer on SG primary side & $\mathrm{X}$ & $\mathrm{X}$ & $\mathrm{X}$ & $\mathrm{O}$ & $\mathrm{X}$ \\
\hline Heat transfer on SG secondary side & $\mathrm{X}$ & $\mathrm{X}$ & $\mathrm{O}$ & $\mathrm{O}$ & $\mathrm{X}$ \\
\hline Pressurizer thermalhydraulics & & & & $\mathrm{X}$ & \\
\hline Surgeline hydraulics & & & & $\mathrm{X}$ & \\
\hline 1-phase 2-phase pumps behavior & & & & $\mathrm{O}$ & \\
\hline Structural heat and heat losses & $\mathrm{X}$ & $\mathrm{X}$ & $\mathrm{X}$ & $\mathrm{O}$ & $\mathrm{X}$ \\
\hline \multicolumn{6}{|l|}{ Noncondensable gas effect } \\
\hline \multicolumn{6}{|l|}{ Boron mixing transport } \\
\hline CET versus PCT relationship & $\mathrm{X}$ & $\mathrm{X}$ & & & \\
\hline
\end{tabular}

$\mathrm{X}$ : totally reproduced, O: partially reproduced.

are scaled up to an NPP nodalization in order to reproduce the same scenario. It allows the behavior of the NPP and ITF nodalizations to be compared under the same conditions in order to check the capabilities of the NPP nodalization and the improvement of nodalization when needed.

In a plant-scaled calculation, experimental conditions and safety actions are adapted without modifying the NPP nodalization. Special care is taken in order to prevent overdetermined systems. The most significant parameters are

(i) steady-state conditions,

(ii) break size,

(iii) break unit and containment,

(iv) core power decay curve (if it is experimentally imposed),

(v) pump coastdown curves (if they are experimentally imposed),

(vi) scram set point,

(vii) isolation set points,

(viii) ECCS's set points,

(ix) ECCS injection curves (pressure versus mass flow curves), (x) blow down set points,

(xi) specifications of the blow down valves (area, opening and closing ratios),

(xii) feed water controller,

(xiii) PZR heater controllers (if this is the case).

The scaling-up adjustment is performed by following the scaling criterion and using scaling factors recalculated for the specific NPP nodalization. These are usually different from those used in the ITF design (related to the ITF reference plant). As explained in $[6,37]$, three scaling criteria can be adopted for designing scaled-down systems:

(i) time reducing or linear scaling,

(ii) time preserving or volume scaling,

(iii) idealized time preserving.

A greater number of ITF tests have been performed in facilities that have been designed using the power-tovolume scaling criterion, which encompasses time preserving scaling. The following scaling-up techniques will be related to the power-to-volume scaling. A further explanation of this criterion can be found in Section 3.4.1.

One of the important points of this activity is the calculation of the NPP scaling factor which was commonly 
computed as the ratio between the primary liquid volume of the NPP and the ITF. This criterion should be revised given that several NPP components (PZR, SG plenums, pumps...) can differ significantly in volume with those of the ITF reference plant and is due to dissimilar design. The authors of the present paper suggest checking which components and parameters have a local scaling factor close to the reference ITF volumetric factor in the ITF system description report. Subsequently the analyst should calculate the scaling factor as an average of the same local factors applied to the chosen NPP. Normally core power, core volume, and total number of U-tubes (for PWR) are a good reference.

As regards the "UPC scaling-up methodology," a plantscaled calculation is a unique calculation with two aims:

(i) to check the applicability of the ITF test in the NPP nodalization for phenomena that have been validated in posttest analyses,

(ii) being a reference for justifying as an expert judgment those discrepancies that appear in comparison with the results of the posttest analysis. Therefore, scaledup and hybrid nodalizations explained in Sections 3.4.2 and 3.5 will be essential.

In the example of Figure 3, it is shown that water is retained in U-tubes during the same period of time for both posttest simulation and plant scaled calculation. In that sense, the calculation is showing the applicability of the transient (phenomena are qualitatively reproduced) which fulfills the first aim. Otherwise, results show an amount of water that is larger in the NPP case. In order to qualify the NPP nodalization, this discrepancy should be explained by carrying out scaling and design effect analyses by taking plant-scaled calculation as a reference for an expert judgment. It is at this point that the second aim is required and this is what distinguishes the "UPC scaling-up methodology" from a simple plant-scaled calculation.

Plant-scaled calculation is unique and cannot be tuned during scaling and design effect analyses. Only if the expert judgment considers that the NPP must be improved should a second calculation be carried out in order to qualify the NPP nodalization improvements.

3.4. Scaling Effect Analyses. This step shows how the scaling criterion affects the simulation of phenomena validated in the ITF posttest analyses. Scaled-up nodalizations are developed at this level by comparing ITF posttest simulation with ITF scaled nodalizations that have the same size as the NPP nodalization.

3.4.1. Power-to-Volume Scaling. Power-to-volume scaling is one of the most common methods used in ITF design. It considers that there is no interaction between different phases of the coolant. Scaling conditions result due to the application of conservation equations (mass, momentum, and energy) under some requirements and implications. Considering one directional flux along the system and normalizing all parameters with respect to its reference scale, the conservation equations applied are

$$
\begin{aligned}
& \frac{\partial \rho^{+}}{\partial t^{+}}+\left[\frac{v_{0} t_{0}}{l_{0}}\right] \frac{\partial \rho^{+} v^{+}}{\partial z^{+}}=0 \\
& \rho^{+} \frac{\partial v^{+}}{\partial t^{+}}+\left[\frac{v_{0} t_{0}}{l_{0}}\right] \rho^{+} v^{+} \frac{\partial v^{+}}{\partial z^{+}}=\left[\frac{\xi_{0}}{A_{c 0}} \frac{q_{0} t_{0}}{\rho_{0} h_{0}}\right] \frac{\xi q^{+}}{A_{c}^{+}} \\
& -\left[\frac{\xi_{0}}{A_{c 0}} K \cdot v_{0} t_{0}\right] \frac{\xi^{+} \pi^{+}}{A_{c}^{+}}-\left[\frac{g t_{0}}{v_{0}}\right] g^{+} \rho^{+} \\
& \rho^{+} \frac{\partial h^{+}}{\partial t^{+}}+\left[\frac{v_{0} t_{0}}{l_{0}}\right] \rho^{+} v^{+} \frac{\partial h^{+}}{\partial z^{+}}=\left[\frac{\xi_{0}}{A_{c 0}} \frac{q_{0} t_{0}}{\rho_{0} h_{0}}\right] \frac{\xi q^{+}}{A_{c}^{+}} \\
& -\left[\frac{P_{0}}{\rho_{0} h_{0}}\right] \frac{\partial P^{+}}{\partial t^{+}}-\left[\frac{v_{0} t_{0}}{l_{0}} \frac{P_{0}}{\rho_{0} h_{0}}\right] v^{+} \frac{\partial P^{+}}{\partial z^{+}} .
\end{aligned}
$$

If pressures, water properties, lenghts, and time are preserved (subindex $R$ of (2) means reference plant):

$$
\frac{P_{R}}{P_{\mathrm{ITF}}}=\frac{\rho_{R}}{\rho_{\mathrm{ITF}}}=\frac{l_{R}}{l_{\mathrm{ITF}}}=\frac{t_{R}}{t_{\mathrm{ITF}}}=1 .
$$

And considering that similarity has been achieved between both systems for (1), the following power-to-volume relations are obtained:

$$
\begin{gathered}
\frac{\phi_{R}}{\phi_{\mathrm{ITF}}}=\frac{W_{R}}{W_{\mathrm{ITF}}}=\frac{Q_{R}}{Q_{\mathrm{ITF}}}=\frac{V_{R}}{V_{\mathrm{ITF}}}=\frac{A_{R}}{A_{\mathrm{ITF}}}=K_{v} \\
{\left[\frac{\xi}{A_{c}} K\right]_{R}=\left[\frac{\xi}{A_{c}} K\right]_{\mathrm{ITF}} .}
\end{gathered}
$$

This demonstration is given in greater detail in [37].

As flow areas change with $K_{v}$, hydraulic diameters will vary from the reference plant to the ITF. The main distortions related to changes in the hydraulic diameter are as follows.

(a) Friction effects: as $K$ depends on the hydraulic diameter, the friction effects-see (4)-are not preserved.

(b) Environment heat losses and passive structure storage energy: the transversal flow surfaces will change with different scaling factors because of the hydraulic diameter, affecting the heat conduction and convection:

$$
\begin{aligned}
\dot{Q}_{\text {ref }} & =-h_{\text {ref }} \cdot A_{\text {ref }}\left(T_{s}-T_{1}\right)=-h_{\mathrm{ITF}} \cdot \pi \cdot D_{\text {ref }} \cdot L_{\text {ref }}\left(T_{s}-T_{1}\right) \\
& =-h_{\mathrm{ITF}} \cdot \pi \cdot \sqrt{K_{v}} \cdot D_{\mathrm{ITF}} \cdot L_{\mathrm{ITF}}\left(T_{s}-T_{1}\right)=\sqrt{K_{v}} \cdot Q_{\mathrm{ITF}} \\
\dot{Q}_{\mathrm{ref}} & =-k_{\mathrm{ref}} \cdot A_{\mathrm{ref}} \frac{\partial T_{\mathrm{ref}}}{\partial x_{\mathrm{ref}}}=-k_{\mathrm{ITF}} \cdot \pi \cdot D_{\mathrm{ref}} \cdot L_{\mathrm{ref}} \frac{\partial T_{\mathrm{ITF}}}{\partial x_{\mathrm{ITF}}} \\
& =-k_{\mathrm{ITF}} \cdot \pi \cdot \sqrt{K_{v}} \cdot D_{\mathrm{ITF}} \cdot L_{\mathrm{ITF}} \frac{\partial T_{\mathrm{ITF}}}{\partial x_{\mathrm{ITF}}}=\sqrt{K_{v}} \cdot Q_{\mathrm{ITF}} .
\end{aligned}
$$

This implies that the ratio between passive heat losses and core heat power will change from the reference plant to the ITF thus generating scaling distortions. 
(c) Froude number: as explained in [38], the Froude number should be preserved in horizontal legs in order to conserve the flow regime transitions (this is neglected in the power-to-volume scaling criterion, which only considers vertical volumes without mixture). In (6) it is shown that the Froude number depends on the hydraulic diameter, affecting its conservation:

$$
\left[\frac{v_{\mathrm{gas}} \cdot \sqrt{\rho_{\mathrm{gas}}}}{\sqrt{g \cdot \Delta \rho \cdot D}}\right]_{\mathrm{ref}}=\left[\frac{v_{\mathrm{gas}} \cdot \sqrt{\rho_{\mathrm{gas}}}}{\sqrt{g \cdot \Delta \rho \cdot D}}\right]_{\mathrm{ITF}} .
$$

3.4.2. Scaled-Up Nodalizations. Scaled-up nodalizations are developed by following certain scaling criterion. The UPC has developed a "Power-to-Volume Scaling Tool (PVST)" which enables RELAP5mod3 input decks to be scaled by following the power-to-volume scaling criterion. This software scales hydrodynamic components, heat structures, control system variables, general tables, and unit trips using an input scaling factor $\left(K_{v}\right)$. Volumes, sections, mass flows, and powers are modified by means of the $K_{v}$ factor. Hydraulic diameters and longitudinal surfaces of the heat structures are changed by using its square root. In the case of hydrodynamic components with parallel channels (such as U-tubes, guide tubes, or fuel rods), the software has the option of keeping geometry values raising their number with the $K_{v}$ factor.

In order to analyze the origin of power-to-volume scaling distortions, two options have been included in the software:

(a) scaling environment and passive heat structures preserving their heat impact whatever the scale,

(b) scaling input nodalizations preserving the Froude number in horizontal components.

To analyze the scaling effect, several scaled-up nodalizations must be generated using the calculated NPP scaling factor (see Section 3.3). The first nodalization has to be a regular scaled-up nodalization, in which the power-tovolume scaling criterion is applied without any modification of the possible scaling distortion sources. Comparison with the ITF posttest calculation will show the effect of the scaling criterion on the analyzed phenomenon. Whenever any distortion is detected, the analyst must perform another scaled-up nodalization without the scaling distortion source. Comparison with the ITF posttest calculation and the regular ITF scaled-up nodalization allows the effect of this specific scaling distortion source to be observed.

This step must be repeated for all the scaling distortions detected until the user achieves an idealized scaled-up nodalization in which the analyzed phenomenon is simulated in the same way as in the ITF posttest analysis.

In [14], three scaled-up nodalizations were produced and compared with the PKL counterpart posttest simulation:

(i) Sc-up nodalization A: a regular scaled-up nodalization,

(ii) Sc-up nodalization B: a regular scaled-up nodalization preserving environment heat losses,
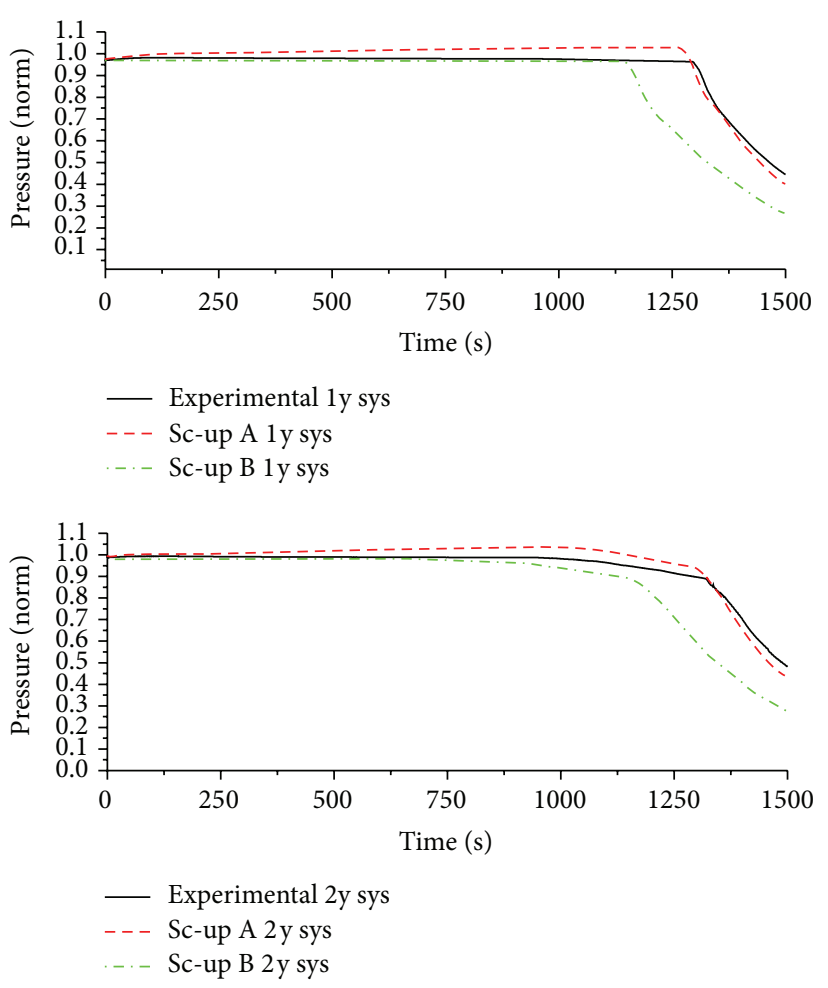

FIGURE 7: System pressures.

(iii) Sc-up nodalization C: a regular scaled-up nodalization preserving environment heat losses and Froude number.

Comparison between the posttest Sc-up nodalization A and Sc-up nodalization B showed that the increasing system pressures during the reflux and condensation phase were due to a decrease in environment heat losses (see Figure 7). Comparison between the posttest, Sc-up nodalization B, and Sc-up nodalization $C$ revealed that the break mass flow discrepancies appeared as a result of a different Froude number (see Figure 8). The main discrepancies in core dryout and peak cladding temperature were removed once these two changes were applied (see Figure 9). It was considered that no further scaling distortion sources needed to be analyzed.

The final result of the analysis carried out in this section is an ITF scaled-up nodalization in which scaling effects were minimized by following the established rationale. Such nodalization will be used in the next step.

3.5. Design Effect Analyses. In this step, the analyst must be able to justify the discrepancies that appear in a plant scaled calculation by means of the differences in design between the ITF and the NPP. In that sense, hybrid nodalizations are compared with the plant scaled calculation and the idealized scaled-up nodalization obtained from the scaling effect analyses. Some components of the NPP nodalization are copied and added to the ITF scaled-up nodalization obtained in the previous step. This allows the impact of each tested component on the simulation to be differentiated. 


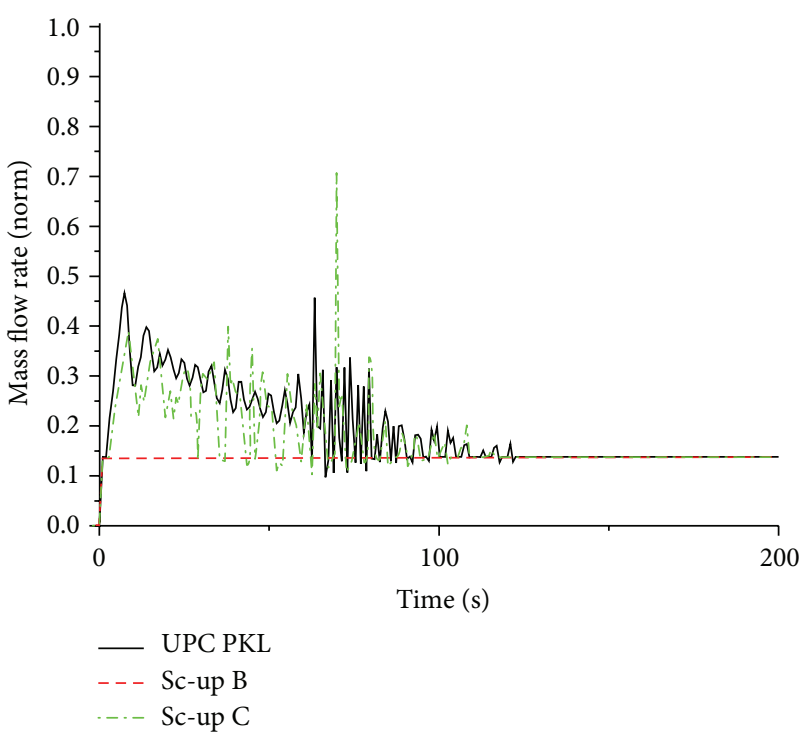

FIGURE 8: Break mass flow rate.

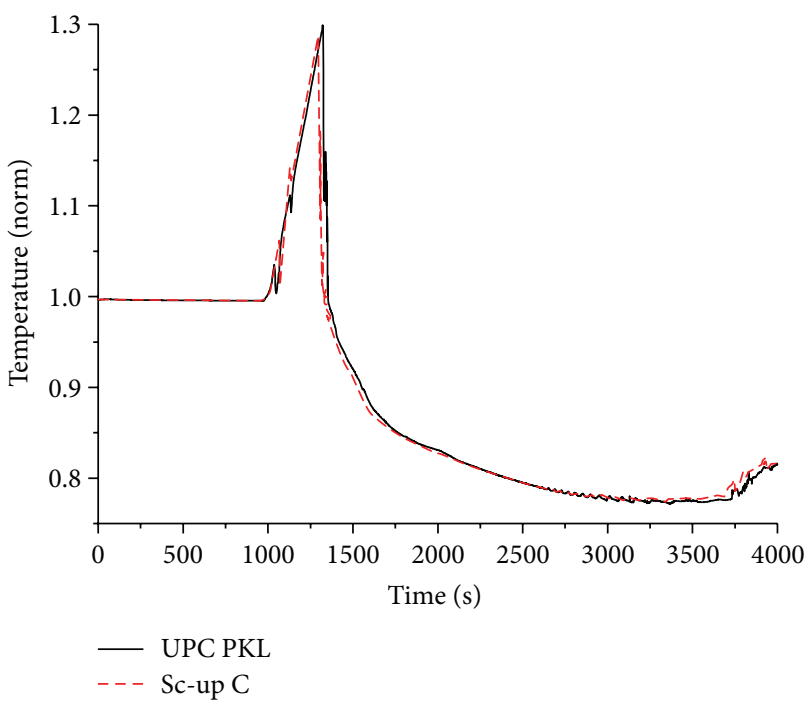

FIgURE 9: Core exit temperature.

The work of the analyst in the design effect analyses has to be focused on two main features:

(a) to identify which components and differences in the configuration might affect the phenomena to be validated;

(b) to develop a group of hybrid nodalizations in series for detecting sources of design distortion. Each component has to be added individually to the previous hybrid nodalization in order to distinguish which components may cause a distortion of the results and which do not. Although some discrepancies could be justified by two or more combined sources of design distortion, it will not be necessary to evaluate them separately as all of them are part of the NPP nodalization. Sequential analyses reveal both the effect of each component and that of them all together.

In [14], a delay in the core dryout (see Figure 10) was detected between PKL and LSTF test simulations. Several design differences were considered that could influence the total inventory and mass distribution:

(i) PZR (differences in scaling ratio-mass of waterand surge line height),

(ii) UTs (differences in exchanging surface that could affect reflux and condensation),

(iii) LSTF downcomer-to-hot leg bypass (which has an effect on water stratification in the hot leg that could modify discharge across the break),

(iv) vessel passive heat structures (could alter vapor generation),

(v) vessel geometries excluding the core (PKL and LSTF vessels have different water distribution around the core as a result of a different reference plant-KWU and Westinghouse, resp.).

Once all possible design distortion sources were listed, hybrid nodalizations were prepared for the idealized scaledup nodalization in which scaling effects were minimized (nodalization C in Figure 9):

(i) PKL hybrid base nodalization: Sc-up nodalization C with LSTF heat losses and LSTF Froude number,

(ii) PKL hybrid A nodalization: PKL hybrid base nodalization with LSTF PZR,

(iii) PKL hybrid B nodalization: PKL hybrid A nodalization with LSTF U-tubes,

(iv) PKL hybrid C nodalization: PKL hybrid B nodalization with LSTF downcomer bypass,

(v) PKL hybrid D nodalization: PKL hybrid C nodalization with LSTF vessel passive heat structures,

(vi) PKL hybrid E nodalization: PKL hybrid D nodalization with LSTF hydrodynamic components, LSTF vessel walls heat structures and LSTF material properties.

Results of Figure 11 showed that PZR design, U-tube design, vessel bypasses, and passive heat structures were not responsible for the delay in core dryout. In fact, design differences between the KWU vessel and Westinghouse vessel were the reason for the delay (Figure 12).

3.6. Expert Judgment. Expert judgment is the final step of the "UPC scaling-up methodology." Once the design effect analysis and ITF posttest analyses modeling have been carried out, the analyst should make a decision on whether the NPP can be considered as qualified for the studied phenomenology or whether the NPP nodalization requires improvement. Expert judgment relies on

(a) the conclusions from the design effect analysis, 


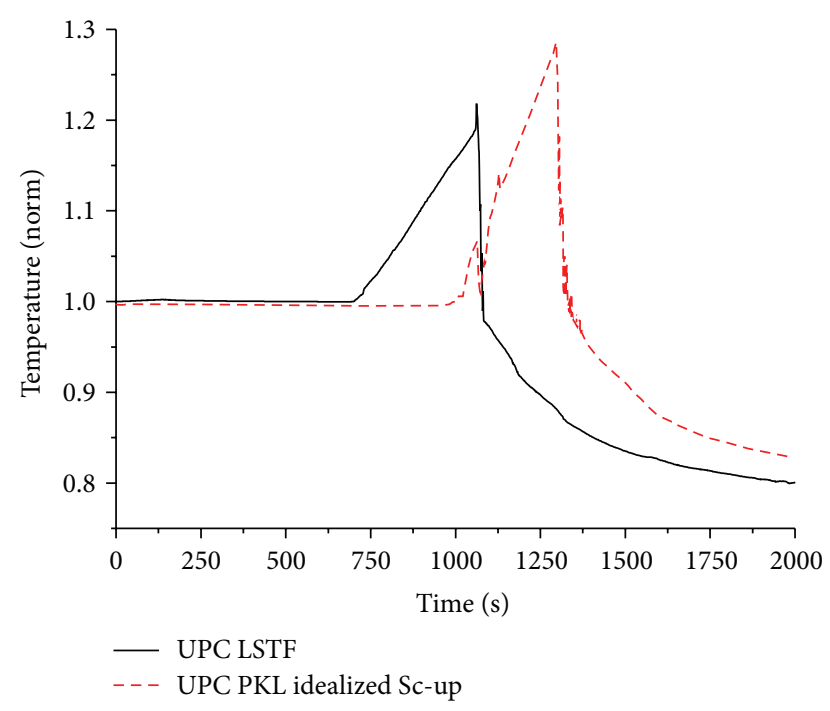

FIgURE 10: Core exite temperature.

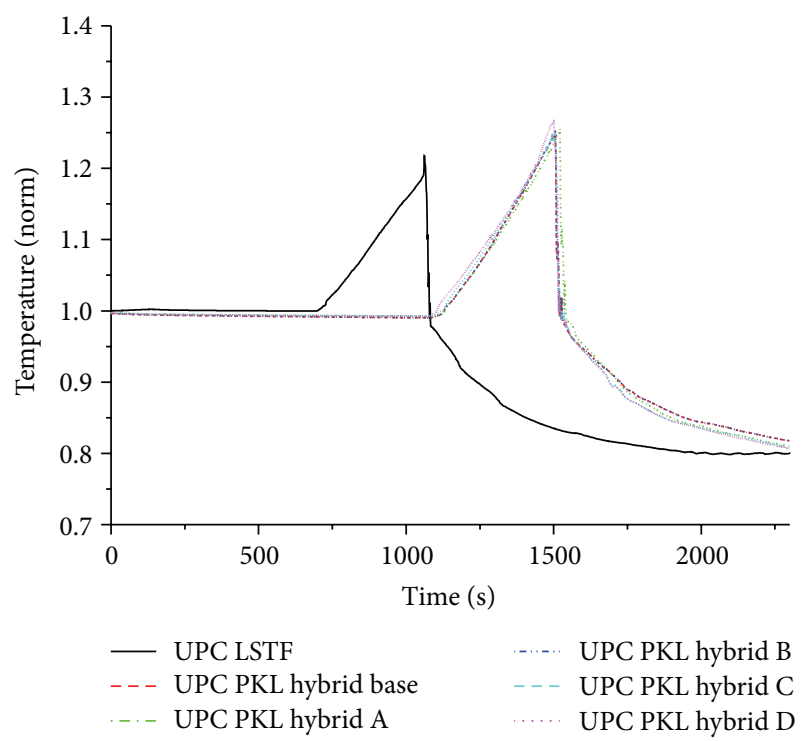

FIGURE 11: Core exite temperature.

(b) the NPP nodalization handbook,

(c) knowledge from ITF modeling.

Once the design effect analysis has been concluded, the user has valuable information about the NPP components that can explain observed discrepancies. When such components are identified, their specification must be thoroughly checked and the analyst must ensure that these components have been consistently modeled. In that sense, the scalingup methodology" is used in the qualification process and continuous improvement of the nodalization.

If the specifications of an NPP component are well transcribed, the analyst, bearing in mind his ITF modeling knowhow, has to judge the significance of the modeling details of the component for the tested phenomena in the specific scenario. If after expert judgment, it is considered

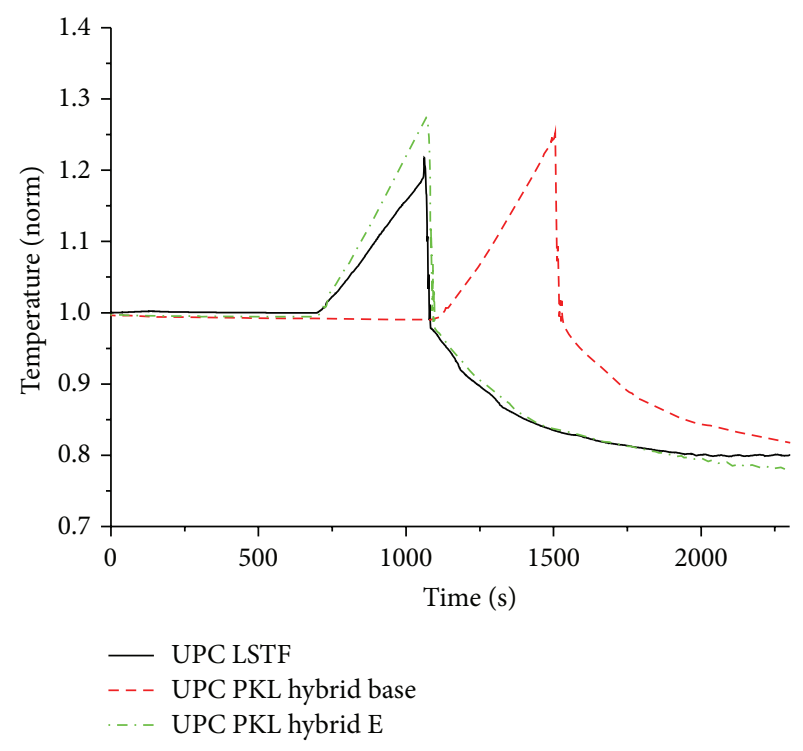

FIGURE 12: Core exite temperature.

that a nodalization improvement is required, a second plant scaled calculation will be necessary, comparing its results with the idealized scaled-up nodalization and one new hybrid nodalization with the new component. Otherwise, it is considered that NPP nodalization is qualified for these phenomena. When all the NPP validation matrix phenomena are validated, the NPP nodalization will be qualified for plant applications and support to plant operation in the specific scenario.

It could occur that after the design effect analysis step, no distortion sources are found that could justify the tested phenomenon discrepancies. In that case, the expert judgment should conclude that the ITF test validation must be reevaluated and the code capabilities be reviewed. In that sense, it would be another evidence of the robustness of the methodology for validating and guaranteeing quality modeling. In any case, in order to avoid these conclusions and to facilitate the work of the analyst, counterpart tests with different scales and designs should be selected to the furthest extent in the NPP scenario validation matrix. These tests should be then validated for the same phenomena with consistent modeling procedures (see Section 3.2).

\section{Conclusions}

Computational analysis and NPP nodalizations have a widely used and sound application on nuclear engineering. In that sense, the quality assurance procedures take a key role in the continuous improvement of NPP integral nodalizations. In the present paper one of the steps of the qualification methodology has been presented in order to take advantage of the modeling experience acquired from the ITF posttest analyses. Three are the pillars that support this systematic procedure: judicial selection of the experimental transients, full confidence in the quality of the ITF simulations, and 
simplicity in justifying discrepancies that appear between ITF- and $K_{v}$-scaled analyses.

Two scaling techniques have been introduced in order to find out how ITF simulated transients change from ITF to NPP nodalizations: the "scaled-up nodalizations," which allow effects of the ITF scaling-down criterion to be checked, and the "hybrid nodalizations," which help the user to establish how design differences modify the results. The exercise of explaining discrepancies between ITF posttests and $K_{v}$ scaled calculations, within the frame of an expert judgment, leads to improved nodalizations with wider reliability and capacity for the given scenarios.

The main concepts and guidelines have been presented along with the rationale of its usage and a representative amount of application results. The presented results are strictly those that are needed to introduce the concepts. Another paper [14] provides greater details on posttest simulations of PKL-LSTF counterpart tests performed within the PKL-2 and ROSA-2 OECD/NEA projects.

Future work will be devoted to enhancing the effectiveness of the tools to a wider field of application.

\section{Nomenclature}

3D: $\quad$ Three-dimensional

A: $\quad$ Area

ANAV: Associació Nuclear Ascó i Vandellós

APEX: Advanced plant experiment

BEPU: Best estimate plus uncertainty

CCFL: Counter current flow limitation

CET: $\quad$ Core exit temperature

CFR: Code of federal regulations

CL: $\quad$ Cold leg

CSAU: Code scaling, applicability, and uncertainty

CSN: Consejo de Seguridad Nuclear

CSNI: Committee on the Safety of Nuclear Installations

D: $\quad$ Pipe diameter

ECCS: Emergency core coolant systems

EOP: $\quad$ Emergency operation procedures

FSA: Fractional scaling analysis

g: $\quad$ Gravitational acceleration

$h$ : Heat transfer coefficient

IAEA: International Atomic Energy Agency

IBLOCA: Intermediate loss-of-coolant accident

ITF: Integral test facility

$k$ : Thermal conductivity

$K: \quad$ Friction factor

$K_{v}: \quad$ Scaling factor

KWU: Kraftwerk Union

$l$ : $\quad$ Length

LOBI: LWR off-normal behaviour investigation

LOCA: Loss-of-coolant accident

LSTSF: Large scale test facility

NEA: Nuclear Energy Agency

NPP: Nuclear power plant

OECD: Organization for Economic Cooperation and Development

$\begin{array}{ll}\text { P: } & \text { Pressure } \\ \text { PCT: } & \text { Peak cladding temperature } \\ \text { PKL: } & \text { Primärkreislauf } \\ \text { PSA: } & \text { Probabilistic safety assessment } \\ \text { PUMA: } & \text { Purdue University Multidimensional Inte- } \\ & \text { gral Test Assembly Facility } \\ \text { PZR: } & \text { Pressurizer } \\ q: & \text { Heat flux } \\ \text { Q: } & \text { Volumetric flow rate } \\ \text { ROSA: } & \text { Rig of safety assessment } \\ \text { SBLOCA: } & \text { Small break loss-of-coolant accident } \\ t: & \text { Time } \\ T: & \text { Temperature } \\ \text { TH: } & \text { Thermal hydraulics } \\ \text { UPC: } & \text { Universitat Politècnica de Catalunya } \\ \text { USNRC: } & \text { United States Nuclear Regulatory } \\ & \text { Commission } \\ v: & \text { Velocity } \\ V: & \text { Volume } \\ \text { VVER: } & \text { Water-Cooled Water-Moderated Power } \\ W: & \text { Reactor } \\ & \text { Mass flow rate. }\end{array}$

Greek Symbols
$\rho:$ Density
$\xi$ : Perimeter
$\Phi$ : Power.

\section{Conflict of Interests}

The authors declare that there is no conflict of interests regarding the publication of this paper.

\section{Acknowledgments}

This paper contains findings that were produced within the OECD-NEA ROSA2 and OECD-NEA PKL2 projects. The authors are grateful to the management board of both projects for their consent to this publication. The authors also want to thank Spanish Safety Council that has partially funded this research.

\section{References}

[1] US NRC, Quantifying Reactor Safety Margins: Application of CSAU to a LBLOCA, NUREG/CR-5249, USNRC, Washington, DC, USA, 1989.

[2] M. Perez, F. Reventos, L. Batet et al., "Uncertainty and sensitivity analysis of a LBLOCA in a PWR nuclear power plant: results of the phase V of the BEMUSE programme," Nuclear Engineering and Design, vol. 241, no. 10, pp. 4206-4222, 2011.

[3] H. Glaeser, "GRS method for uncertainty and sensitivity evaluation of code results and applications," Science and Technology of Nuclear Installations, vol. 2008, Article ID 798901, 7 pages, 2008.

[4] F. D’Auria and W. Giannotti, "Development of a code with the capability of internal assessment of uncertainty," Nuclear Technology, vol. 131, no. 2, pp. 159-196, 2000. 
[5] M. Ishii, S. T. Revankar, T. Leonardi et al., "The three-level scaling approach with application to the Purdue University Multi-Dimensional Integral Test Assembly (PUMA)," Nuclear Engineering and Design, vol. 186, no. 1-2, pp. 177-211, 1998.

[6] F. D’Auria and G. M. Galassi, "Scaling in nuclear reactor system thermal-hydraulics," Nuclear Engineering and Design, vol. 240, no. 10, pp. 3267-3293, 2010.

[7] N. Zuber, A Hierarchical Two-Twiered Scaling Analysis, NUREG/CR-5809, USNRC, Washington, DC, USA.

[8] N. Zuber, G. E. Wilson, M. Ishii et al., "An integrated structure and scaling methodology for severe accident technical issue resolution: development of methodology," Nuclear Engineering and Design, vol. 186, no. 1-2, pp. 1-21, 1998.

[9] J. N. Reyes Jr. and L. Hochreiter, "Scaling analysis for the OSU AP600 test facility (APEX)," Nuclear Engineering and Design, vol. 186, no. 1-2, pp. 53-109, 1998.

[10] N. Zuber, W. Wulff, U. S. Rohatgi, and I. Catton, "Application of fractional scaling analysis (FSA) to loss of coolant accidents (LOCA). Part 1: methodology development," in Proceedings of the International Topical Meeting on Nuclear Reactor ThermalHydraulics (NURETH-11 '05), Avignon, France, 2005.

[11] W. Wulff, N. Zuber, U. S. Rohatgi, and I. Catton, "Application of fractional scaling analysis (FSA) to loss of coolant accidents (LOCA). Part 2: system level scaling for system depressurization," in Proceedings of the International Topical Meeting on Nuclear Reactor Thermal-Hydraulics (NURETH-11 '05), Avignon, France, 2005.

[12] I. Catton, W. Wulff, N. Zuber, and U. S. Rohatgi, "Application of fractional scaling analysis (FSA) to loss of coolant accidents (LOCA). Part 3: component level scaling for peak clad temperature," in Proceedings of the International Topical Meeting on Nuclear Reactor Thermal-Hydraulics (NURETH-11 '05), Avignon, France, 2005.

[13] F. D'Auria, N. Debrecin, and G. M. Galassi, "Outline of the uncertainty methodology based on accuracy extrapostion (UMAE)," Nuclear Technology, vol. 109, no. 1, pp. 21-38, 1995.

[14] V. Martínez, F. Reventós, and J. Freixa, "Applying UPC scalingup methodology to the LSTF-PKL counterpart test," Science and Technology of Nuclear Installations. In press.

[15] Accident Analysis for Nuclear Power Plants, Safety Reports Series 23, IAEA, Vienna, Austria, 2002.

[16] Development and Review of Plant Specific Emergency Operating Procedures, Safety Reports Series 48, IAEA, Vienna, Austria, 2006.

[17] F. Reventos, L. Batet, C. Llopis, C. Pretel, and I. Sol, “Thermalhydraulic analysis tasks for ANAV NPPs in support of plant operation and control," Science and Technology of Nuclear Installations, vol. 2008, Article ID 153858, 13 pages, 2008.

[18] F. Reventós, C. Llopis, L. Batet, C. Pretel, and I. Sol, "Analysis of an actual reactor trip operating event due to a high variation of neutron flux occurring in the Vandellòs-II nuclear power plant," Nuclear Engineering and Design, vol. 240, no. 10, pp. 2999-3008, 2010.

[19] C. Llopis, F. Reventós, L. Batet, C. Pretel, and I. Sol, “Analysis of low load transients for the Vandellòs-II NPP. Application to operation and control support," Nuclear Engineering and Design, vol. 237, no. 18, pp. 2014-2023, 2007.

[20] F. Reventós, L. Batet, C. Llopis, C. Pretel, M. Salvat, and I. Sol, "Advanced qualification process of ANAV NPP integral dynamic models for supporting plant operation and control," Nuclear Engineering and Design, vol. 237, no. 1, pp. 54-63, 2007.
[21] A. Cuadra, J.-L. Gago, and F. Reventós, "Analysis of a main steam line break in ascó nuclear power plant," Nuclear Technology, vol. 146, no. 1, pp. 41-48, 2004.

[22] L. Garcia-Delgado, M. T. Lopez-Carbonell, and I. GomezBernal, "Fuel and core design experiences in cofrentres NPP," in Proceedings of the International Conference of Asian Political Parties (ICAPP '02), 2002.

[23] G. Aprile, F. D’Auria, M. Frogheri, and G. M. Galassi, "Application of a qualified WWER-1000 plant nodalization for Relap5/mod3.2 computer code," in Proceedings of the International Conference on Nuclear Option in Countries with Small and Medium Electricity Grid, Opatjia, Croatia, 1996.

[24] M. Bonuccelli, F. D'Auria, N. Debrecin, and G. M. Galassi, "A methodology for the qualification of thermal-hydraulic codes nodalizations," in Proceedings of the International Topical Meeting on Nuclear Reactor Thermal-Hydraulics (NURETH-6 '93), Grenoble, France, 1993.

[25] V. Martínez, F. Reventós, C. Pretel, and I. Sol, "Code validation and scaling of the ROSA/LSTF test 3-1 experiment," in Proceedings of the International Topical Meeting on Safety of Nuclear Installations (TopSafe'08), Dubrovnik, Croatia, October 2008.

[26] P. Pla, F. Reventós, C. Pretel, W. Giannotti, F. D’Auria, and A. Annunziato, "Code validation and scaling of the LOBI BL-30 experiment," in Proceedings of the International Congress on Aids in Asia and the Pacific (ICCAP '07), Nice, France, May 2007.

[27] S. Petelin, B. Mavko, B. Končar, and Y. Hassan, "Scaling of the small-scale thermal-hydraulic transient to the real nuclear power plant," Nuclear Technology, vol. 158, no. 1, pp. 56-68, 2007.

[28] J. Freixa, F. Reventós, C. Pretel, L. Batet, and I. Sol, "SBLOCA with boron dilution in pressurized water reactors. Impact on operation and safety," Nuclear Engineering and Design, vol. 239, no. 4, pp. 749-760, 2009.

[29] J. Freixa and A. Manera, "Verification of a TRACE EPR model on the basis of a scaling calculation of an SBLOCA ROSA test," Nuclear Engineering and Design, vol. 241, no. 3, pp. 888-896, 2011.

[30] OECD/NEA, CSNI Code Validation Matrix of ThermoHydraulic Codes for LWR LOCA and Transients, 132-rev. 1, CSNI, Paris, France, 1996.

[31] F. Reventós, P. Pla, C. Matteoli et al., "Consistent posttest calculations for LOCA scenarios in LOBI integral facility," Science and Technology of Nuclear Installations, vol. 2012, Article ID 474162, 16 pages, 2012.

[32] J. Freixa and A. Manera, "Remarks on consistent development of plant nodalizations: an example of application to the ROSA integral test facility," Science and Technology of Nuclear Installations, vol. 2012, Article ID 158617, 17 pages, 2012.

[33] V. Martínez, F. Reventós, and C. Pretel, "Post-Test Calculation of the ROSA/LSTF Test 3-1 using RELAP5/mod3.3," NUREG/IA409, 2012.

[34] V. Martínez, F. Reventós, and C. Pretel, "Post-Test Calculation of the ROSA/LSTF Test 3-2 using RELAP5/mod3.3," NUREG/IA410, 2012.

[35] J. Freixa, SBLOCA with boron dilution in pressurized water reactors. Impact to the operation and safety [Ph.D. thesis], Universitat Politècnica de Catalunya, DFEN, 2007.

[36] J. Freixa, F. Reventós, C. Pretel, and L. Batet, "Boron transport model with physical diffusion for RELAP5," Nuclear Technology, vol. 160, no. 2, pp. 205-215, 2007. 
[37] A. N. Nahavandi, F. S. Castellana, and E. N. Moradkhanian, "Scaling laws for modeling nuclear reactor systems," Nuclear Science and Engineering, vol. 72, no. 1, pp. 75-83, 1979.

[38] N. Zuber, "Problems in modeling of small break LOCA," Appendix B, NUREG-0724, 1980. 


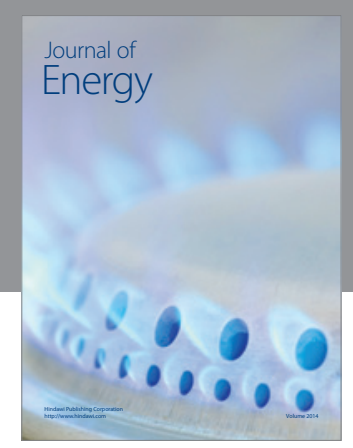

Journal of

Industrial Engineering
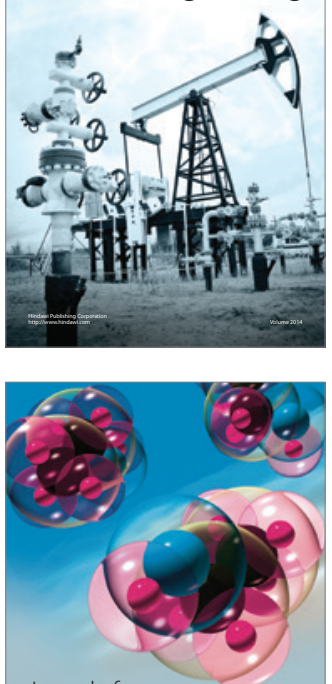

Fuels
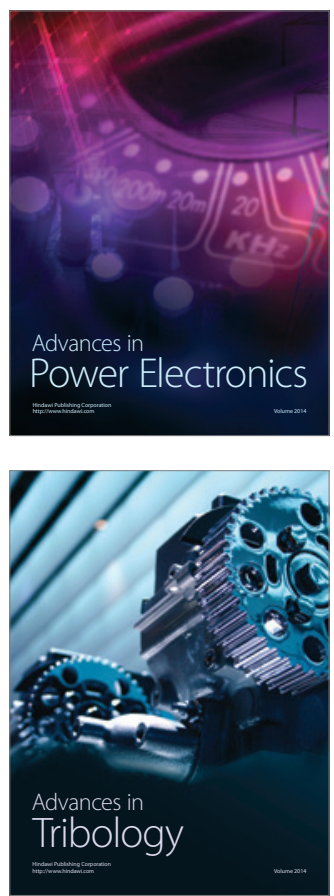

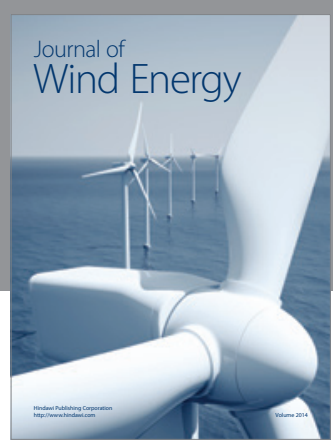

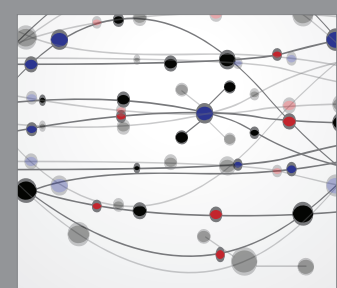

The Scientific World Journal

Submit your manuscripts at http://www.hindawi.com

Journal of

Structures
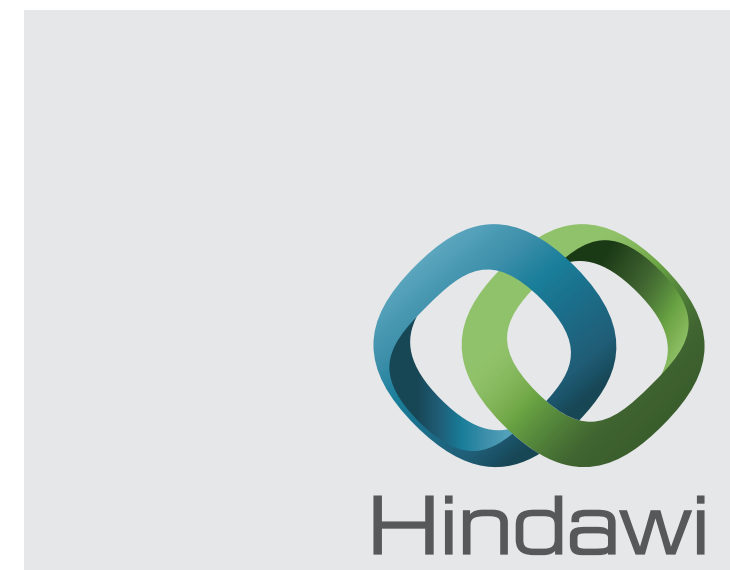

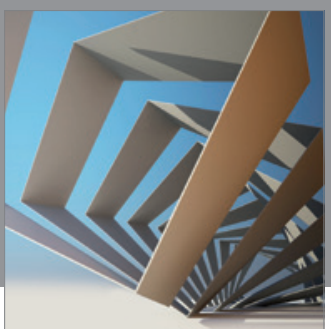

Rotating

Machinery
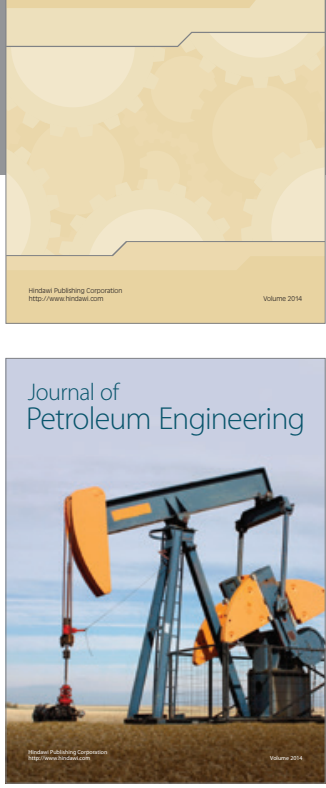

Journal of

Solar Energy
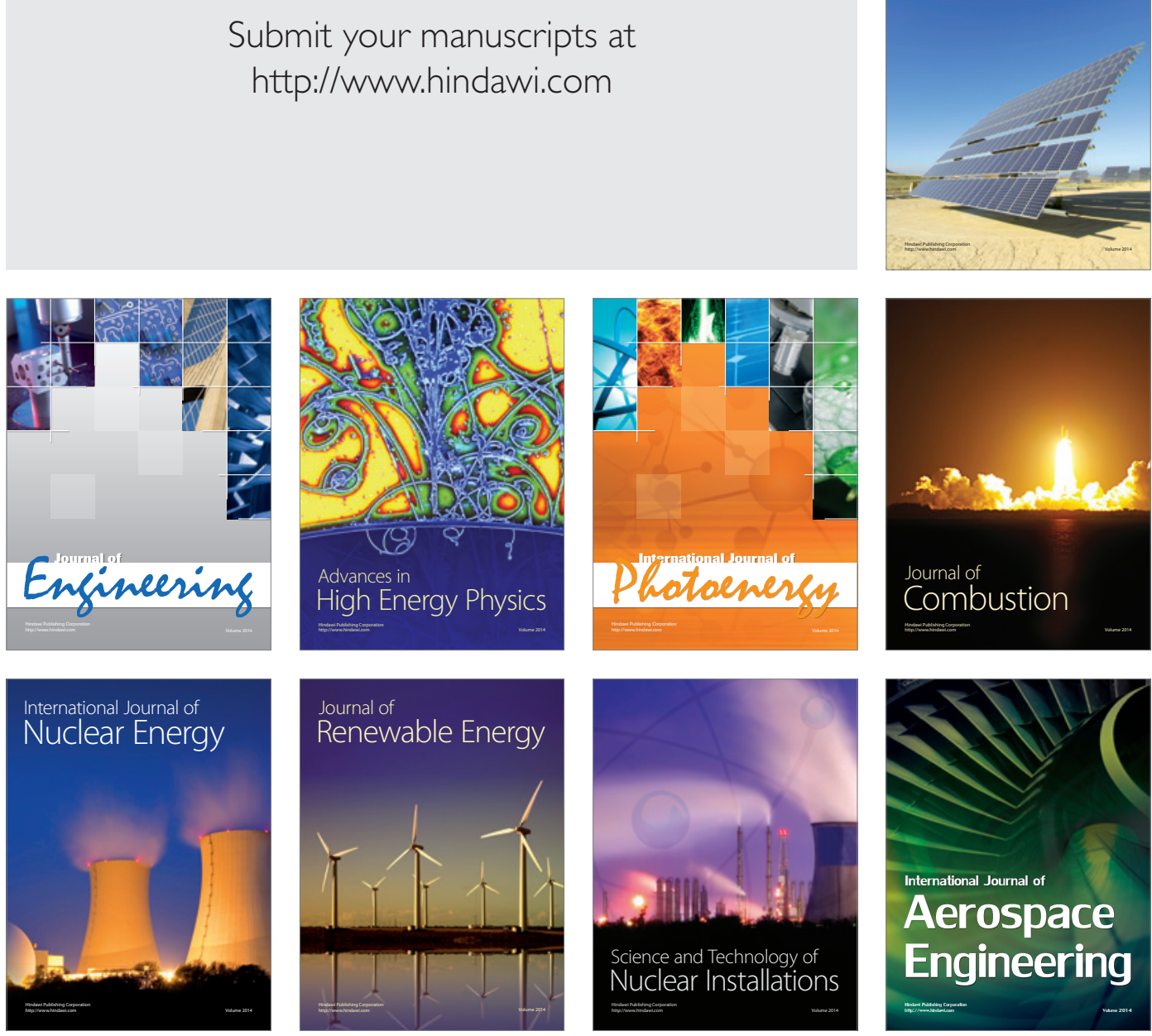